\title{
IEDITORIAL
}

\section{Who should manage comatose post-cardiac arrest patients?}

\author{
Johannes Grand, Christian Hassager, Jesper Kjaergaard \\ Cardiac Intensive Care Unit, Department of Cardiology, Copenhagen University Hospital, Rigshospitalet, Copenhagen, Denmark
}

\section{RELATED ARTICLE} by Kowalik et al, see p. 30
Correspondence to: Johannes Grand, MD, Department of Cardiology B, Section 2142, Copenhagen University Hospital, Rigshospitalet, Blegdamsvej 9 , 2100 Copenhagen, Denmark, phone: +4535456398 email: johannes.grand@regionh.dk Received: December 22, 2019. Accepted: December 26, 2019. Published online: January 24, 2020. Kardiol Pol. 2020; 78 (1): 4-5 doi:10.33963/KP.15154 Copyright by the Author(s), 2020
Despite extensive research during the last decades, resuscitated, but comatose, patients with out-of-hospital cardiac arrest (OHCA) still have a poor prognosis with an estimated in-hospital mortality of $30 \%$ to $50 \%$. ${ }^{1}$ The high in-hospital mortality is related to organ dysfunction following whole-body ischemia. The clinical presentation of these patients has been termed the "postcardiac arrest syndrome" (PCAS), consisting of myocardial dysfunction, ischemia-reperfusion injury, anoxic brain injury, and a potential precipitating pathology that led to the arrest. ${ }^{2}$ The single most important component of PCAS is anoxic brain injury, which is also the primary cause of mortality and neurologic sequelae., ${ }^{1,3}$

Several initiatives have been investigated to improve outcome after OHCA, but mitigation of brain injury has proved surprisingly difficult in the postresuscitation phase. Today, the only guideline-recommended treatment of anoxic brain injury is targeted temperature management (TTM). ${ }^{4}$ This treatment was first investigated at a temperature of $32^{\circ} \mathrm{C}$ to $34^{\circ} \mathrm{C}$ in humans and reported in 2002,5,6 leading to its implementation in international guidelines in the subsequent years. In 2013, an international multicenter TTM trial reported on 939 comatose OHCA survivors randomized to 24 hours of TTM at $33^{\circ} \mathrm{C}$ vs $36^{\circ} \mathrm{C}$ and found equal efficacy of the 2 temperature strata. ${ }^{7}$ Also, duration of TTM was investigated, with no benefit shown for TTM of 48 hours as compared with that of 24 hours. ${ }^{8}$ However, the means of inducing and maintaining TTM may be important, since a recent systematic review found that intravascular temperature control was associated with improved neurologic outcome compared with surface cooling methods. ${ }^{9}$ Consequently, TTM is a complex treatment requiring specialized intensive care units and personnel with experience in the management of patients with PCAS. However, it is not the only treatment modality needed to treat these patients. Acute myocardial infarction as a precipitating cause of the arrest may require an urgent primary coronary intervention. ${ }^{4}$ Global ischemia-reperfusion injury leading to sepsis-like vasoplegia and hemodynamic instability requires the use of vasopressors in most patients. Low cardiac output and reversible myocardial dysfunction may require fast access to echocardiography and, in some cases, specialist treatment. These highly specialized treatment modalities encompass both anesthesiologic and cardiologic expertise, which can be unified in intensive cardiac care units (ICCUs), specializing in the management of acute and intensive cardiovascular conditions. ${ }^{10}$

In this issue of Kardiologia Polska (Kardiol Pol, Polish Heart Journal), Kowalik et al ${ }^{11}$ aimed to compare the TTM procedures and patient outcomes between intensive care units (ICUs) and ICCUs using a Polish registry of 377 patients with OHCA from 16 ICCUs and 10 ICUs. The study is important because until now no studies have compared treatment and outcomes between the ICU and ICCU. The study first and foremost identified some differences in treatment strategies in which utilization of coronary angiography, use of intra-aortic balloon pump, and infusions of dopamine and dobutamine were more frequent in the ICCUs, whereas the use of norepinephrine was more frequent in the ICUs. However, this is likely a result of differences in patient characteristics. Regarding outcome, pneumonia and acute renal failure were more frequent in ICCUs, but no differences 
were found for mortality or neurologic outcome. The most interesting finding was that intravascular temperature control was more frequent and time until induction of TTM was shorter (median, 83 [IQR, 35-125] minutes vs 175 [IQR, 80-230] minutes) in ICCUs, which could be regarded as a qualitative outcome measure.

Due to the intrinsic bias of the retrospective observational design, we refrain from concluding any causality between the ICCUs and more favorable TTM characteristics. Differences in TTM data and patient outcome are possibly related to differences between centers (tertiary heart center vs local hospital), and these data were not reported. This hypothesis is supported by the fact that more ICCU patients had ST-segment elevations on admission (53\% vs $35 \%$ ), which is likely a consequence of prehospital triage. A number of studies have reported that direct admission to a tertiary heart center was associated with improved outcome even after adjustment for baseline characteristics and comorbidities. ${ }^{12-14}$ The study by Kowalik et $\mathrm{a}^{11}$ was based on a prespecified questionnaire, which is likely the cause of the limited data regarding TTM induction, maintenance, and rewarming. Furthermore, this registry is relatively small, and we encourage the authors to expand the registry to continue ensuring the quality of TTM in Poland. This study should serve as an example for a larger European registry of TTM data, in which differences in TTM methods, the level of target temperatures, and the time until the target temperature is reached could be investigated.

The study by Kowalik et al ${ }^{11}$ does not answer the question of who should manage post-cardiac arrest patients, and these patients require both specific technical cardiovascular interventions and monitoring in addition to complex intensive care. Randomized trials comparing ICUs and ICCUs are most likely not feasible. However, a close relationship and cooperation between the ICU or ICCU and other specialties remains essential for optimal patient management. If patients with $\mathrm{OHCA}$ are admitted to regular ICUs, it is important that echocardiography and angiography are readily available and that cardiologists are involved in patient management already at an early stage.

\section{ARTICLE INFORMATION}

DISCLAIMER The opinions expressed by the author are not necessarily those of the journal editors, Polish Cardiac Society, or publisher.

CONFLICT OF INTEREST None declared.

OPEN ACCESS This is an Open Access article distributed under the terms of the Creative Commons Attribution-NonCommercial-NoDerivatives 4.0 International License (CC BY-NC-ND 4.0), allowing third parties to download articles and share them with others, provided the original work is properly cited, not changed in any way, distributed under the same license, and used for noncommercial purposes only. For commercial use, please contact the journal office at kardiologiapolska@ptkardio.pl.

HOW TO CITE Grand J, Hassager C, Kjaergaard J. Who should manage comatose post-cardiac arrest patients? Kardiol Pol. 2020; 78: 4-5. doi:10.33963/KP.15154

\section{REFERENCES}

1 Laver S, Farrow C, Turner D, Nolan J. Mode of death after admission to an intensive care unit following cardiac arrest. Intensive Care Med. 2004; 30: 2126-2128. 2 Neumar RW, Nolan JP, Adrie C, et al. Post-cardiac arrest syndrome: epidemiology, pathophysiology, treatment, and prognostication. A consensus statement from the International Liaison Committee on Resuscitation (American Heart Association, Australian and New Zealand Council on Resuscitation, European Resuscitation Council, Heart and Stroke Foundation of Canada, InterAmerican Heart Foundation, Resuscitation Council of Asia, and the Resuscitation Council of Southern Africa); the American Heart Association Emergency Cardiovascular Care Committee; the Council on Cardiovascular Surgery and Anesthesia; the Council on Cardiopulmonary, Perioperative, and Critical Care; the Council on Clinical Cardiology; and the Stroke Council. Circulation. 2008; 118: 2452-2483.

3 Cronberg T, Lilja G, Horn J, et al. Neurologic function and health-related quality of life in patients following targeted temperature management at $33^{\circ} \mathrm{C}$ vs $36^{\circ} \mathrm{C}$ after out-of-hospital cardiac arrest: a randomized clinical trial. JAMA Neurol. 2015; 72: 634-641.

4 Nolan JP, Soar J, Cariou A, et al. European Resuscitation Council and European Society of Intensive Care Medicine guidelines for post-resuscitation care 2015: Section 5 of the European Resuscitation Council Guidelines for Resuscitation 2015. Resuscitation. 2015; 95: 202-222.

5 Bernard SA, Gray TW, Buist MD, et al. Treatment of comatose survivors of out-of-hospital cardiac arrest with induced hypothermia. N Engl J Med. 2002; 346: 557-563.

6 Hypothermia after Cardiac Arrest Study Group. Mild therapeutic hypothermia to improve the neurologic outcome after cardiac arrest. N Engl J Med. 2002; 346: 549-556.

7 Nielsen N, Wetterslev J, Cronberg T, et al. Targeted temperature management at $33^{\circ} \mathrm{C}$ versus $36^{\circ} \mathrm{C}$ after cardiac arrest. $\mathrm{N}$ Engl J Med. 2013; 369: 2197-2206.

8 Kirkegaard H, Søreide E, de Haas I, et al. Targeted temperature management for 48 vs 24 hours and neurologic outcome after out-of-hospital cardiac arrest: a randomized clinical trial. JAMA. 2017; 318: 341-350.

9 Bartlett E, Valenzuela T, Idris A, et al. Systematic review and meta-analysis of INTRAvascular temperature management versus surface cooling in COMATose patients resuscitated from cardiac arrest. Resuscitation. 2019 Nov 12. [Epub ahead of print].

10 Bonnefoy-Cudraz E, Bueno H, Casella G, et al. Editor's choice - Acute Cardiovascular Care Association position paper on intensive cardiovascular care units: an update on their definition, structure, organisation and function. Eur Heart J Acute Cardiovasc Care. 2018; 7: 80-95.

11 Kowalik RJ, Fojt A, Ozierański K, et al. Results of targeted temperature management of patients after sudden out-of-hospital cardiac arrest: a comparison between intensive general and cardiac care units. Kardiol Pol. 2020; 78: 30-36.

12 Tranberg T, Lippert FK, Christensen EF, et al. Distance to invasive heart centre, performance of acute coronary angiography, and angioplasty and associated outcome in out-of-hospital cardiac arrest: a nationwide study. Eur Heart J. 2017; 38: $1645-1652$.

13 Søholm H, Kjaergaard J, Bro-Jeppesen J, et al. Prognostic implications of level-of-care at tertiary heart centers compared with other hospitals after resuscitation from out-of-hospital cardiac arrest. Circ Cardiovasc Qual Outcomes. 2015; 8: 268-276.

14 Søholm H, Wachtell K, Nielsen SL, et al. Tertiary centres have improved survival compared to other hospitals in the Copenhagen area after out-of-hospital cardiac arrest. Resuscitation. 2013; 84: 162-167. 